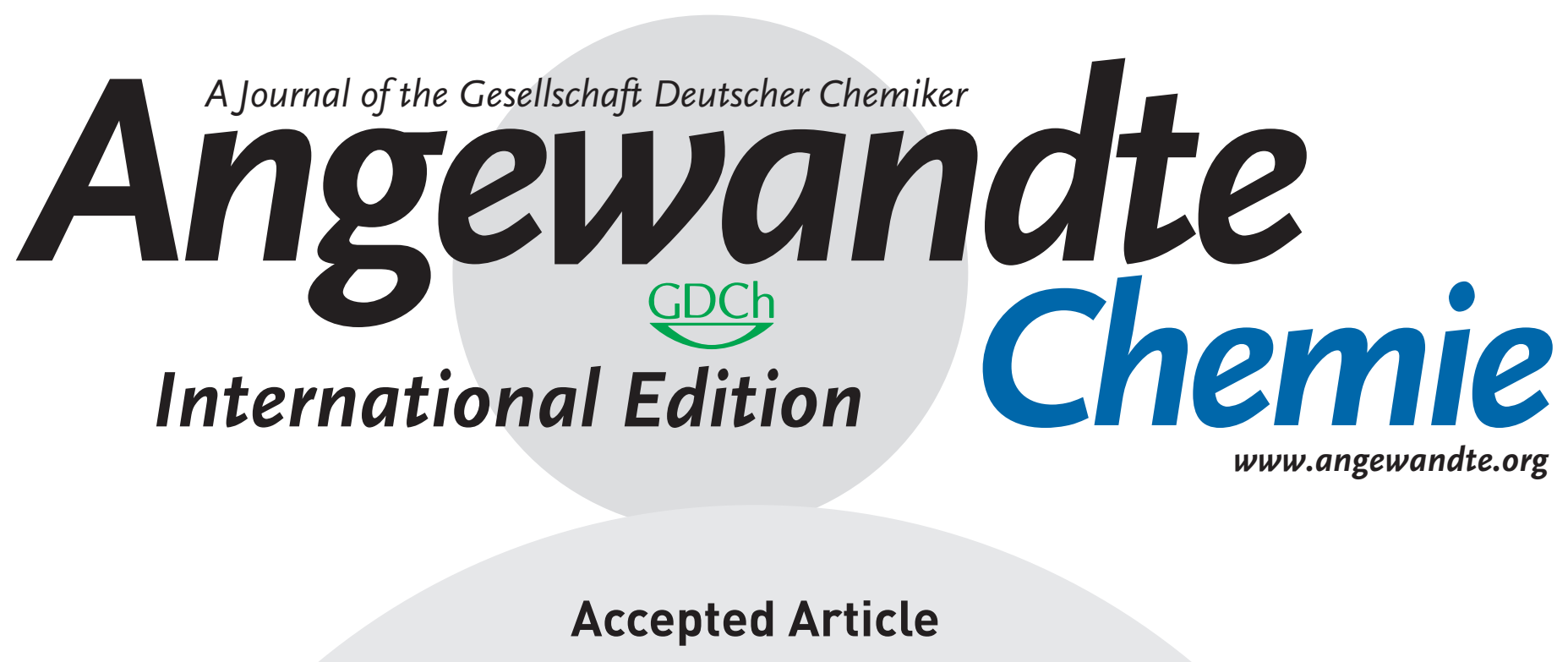

Title: Electrochemical Fluorination of Vinyl Boronates through DonorStabilized Vinyl Carbocation Intermediates

Authors: Hosea M. Nelson, Benjamin Wigman, Woojin Lee, Wenjing Wei, and K. N. Houk

This manuscript has been accepted after peer review and appears as an Accepted Article online prior to editing, proofing, and formal publication of the final Version of Record (VoR). The VoR will be published online in Early View as soon as possible and may be different to this Accepted Article as a result of editing. Readers should obtain the VoR from the journal website shown below when it is published to ensure accuracy of information. The authors are responsible for the content of this Accepted Article.

To be cited as: Angew. Chem. Int. Ed. 2022, e202113972

Link to VoR: https://doi.org/10.1002/anie.202113972 


\title{
Electrochemical Fluorination of Vinyl Boronates through Donor- Stabilized Vinyl Carbocation Intermediates
}

\author{
Benjamin Wigman ${ }^{a}$, Woojin Lee ${ }^{a}$, Wenjing Wei ${ }^{a}$, K. N. Houk ${ }^{a^{*}}$, Hosea M. Nelson ${ }^{b^{*}}$
}

[a] B. Wigman, W. Lee, W. Wei, Prof. Dr. K. N. Houk

Department of Chemistry and Biochemistry

University of California, Los Angeles

Los Angeles, CA 90095 (USA)

E-mail: houk@chem.ucla.edu

[b] Prof. Dr. H. M. Nelson

Department of Chemistry and Chemical Engineering

California Institute of Technology

Pasadena, CA 91125 (USA)

E-mail: hosea@caltech.edu

Supporting information for this article is given via a link at the end of the document.

\begin{abstract}
The electrochemical generation of vinyl carbocations from alkenyl boronic esters and boronates is reported. Using easy-tohandle nucleophilic fluoride reagents, these intermediates are trapped to form fully substituted vinyl fluorides. Mechanistic studies support the formation of dicoordinated carbocations through sequential single-electron oxidation events. Notably, this electrochemical fluorination features fast reaction times and Lewis acid-free conditions. This transformation provides a complementary method to access vinyl fluorides with simple fluoride salts such as TBAF.
\end{abstract}

Carbocations, a common synthon in synthetic organic chemistry logic, have been studied for more than 100 years. ${ }^{1}$ While the reactivities and properties of alkyl carbocations have been the main focus of these studies, highly reactive vinyl carbocations and their ensuing bond-forming reactions have been the subject of far fewer research efforts. Nonetheless, vinyl cations have been isolated and characterized in the solid state ${ }^{2 a, b}$, revealing their remarkable linear geometry, and have been generated by a variety of conditions including solvolysis ${ }^{2 c}$, photolysis ${ }^{2 d-f}$, leaving group abstraction ${ }^{2 g-j}$, and alkyne protonation/transition metal-activation ${ }^{2 k, 1}$. With the exceptions of photolysis, which requires high-energy UV light, and solvolysis, which requires high temperatures, vinyl cation generation often relies on potent Lewis or Brønsted acids that can be poisoned by heteroatoms and requires rigorous air-free handling. At the outset of the current study, we hypothesized that these reactive intermediates could instead be generated via consecutive singleelectron oxidation events, analogous to the Hofer-Moest electrochemical oxidation of alkyl carboxylates to alkyl carbocations (Scheme 1a). ${ }^{3 a, b}$ Electrochemical oxidation has become a powerful strategy to generate a variety of reactive cationic intermediates, as is demonstrated in the cation pool method. ${ }^{3 c, d}$ This unconventional approach to generating these high-energy species could allow for milder and less stringent reaction conditions, perhaps enabling the discovery of new chemical transformations. Here, we report our initial studies in this area, where alkenyl boronates are converted to vinyl fluorides electrochemically through nucleophilic trapping of vinyl carbocation intermediates (Scheme 1b). While vinyl fluorides have well established syntheses, including but not limited to Wittig olefination reactions, addition to alkynes and allenes, and transition metal-catalyzed cross-coupling reactions, we believe this report serves as a complementary and potentially divergent method to gain access to a variety of vinyl halides as well as other olefinic products due to the vinyl carbocation generated. ${ }^{4}$

Inspired by the Hofer-Moest oxidation and reports of generation of alkyl carbocations from redox-active esters, ${ }^{3,5}$ attempts at oxidation of carboxylate derivatives by means of various photochemical, electrochemical, and chemical processes provided intractable mixtures of products that gave no evidence for vinyl carbocation formation. ${ }^{6}$ We turned to other redox active groups, particularly trifluoroborates, (Table 1) since these are known to undergo single electron oxidation. ${ }^{7}$ We were gratified to find that electrolysis in an undivided cell of vinyl trifluoroborate 1 with a platinum cathode and carbon anode at a constant working potential of $+1.8 \mathrm{~V}$ vs SCE in dichloromethane (DCM) with tetrabutylammonium fluoride trihydrate (TBAF) as a trapping agent produced vinyl fluoride 2 in $42 \%$ yield by ${ }^{19} \mathrm{~F}$ NMR (Table 1, entry 1 ) after only 15 minutes. The styrenyl position was key for reactivity, as non-styrenyl boronates were not competent for this transformation. ${ }^{6}$ In this solvent, however, the vinyl chloride product was also observed in $20 \%$ yield by ${ }^{1} \mathrm{H}$ NMR, presumably from reduction of DCM to produce the chloride anion. Switching the solvent to tetrahydrofuran (THF) or dimethylformamide (DMF) (entries 2,3) led to trace or no product respectively; ultimately use of acetonitrile (MeCN) yielded vinyl fluoride 2 in $65 \%$ isolated yield with no vinyl chloride impurity (entry 4 ). We also examined vinyl pinacol boronate $\mathbf{3}$, as more electron-rich boronates have been demonstrated to have a profound effect on the oxidation potential of the substrate. ${ }^{8}$ Pinacol boronate (BPinF) $\mathbf{3}$ was generated in situ from the starting pinacol boronic ester: ${ }^{11} \mathrm{~B}$ NMR studies indicated that the boronate was fully formed in solution with 3 equivalents of TBAF. ${ }^{6}$ We believe the anionic boronate complex to a) Hofer-Moest Oxidation

Access to alkyl carbocations

$$
\overbrace{}^{\mathrm{CO}_{2} \mathrm{H}} \frac{\mathrm{Pt}(-) / \mathrm{Pt}(+)}{-2 \mathrm{e}^{-},-\mathrm{CO}_{2}}\left[{ }^{\oplus}{ }_{\mathrm{MeOH}}^{\mathrm{OMe}}\right.
$$

b) Electrochemical fluorination of vinyl boronates

This research, via putative vinyl carbocations

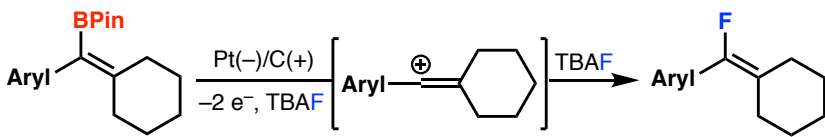

Scheme 1. Previous work and this study. (a) Hofer-Moest electrochemical oxidation. (b) this research: electrochemical fluorination of alkenyl boronates via vinyl carbocations.

be the redox active intermediate, as without this fluoride additive no reaction occurs. Subjecting this pinacol boronate $(3)$ to the reaction conditions yielded vinyl fluoride 2 in a slightly increased $70 \%$ isolated yield (entry 5). Other electrolytes, fluoride sources, and equivalents of TBAF led to diminished yield (entries 6-12). The remaining mass balance for these reactions are ketone and enone products, the latter presumably arising from oxidation of the ketone, which we attribute to water quenching of a vinyl carbocation intermediate. ${ }^{6}$ It is noteworthy that this reaction does not need to be carried out under rigorously anhydrous conditions, likely due to the high nucleophilicity of the fluoride anion. We believe water to serve as the sacrificial oxidant, and attempts to perform the reaction under water-free conditions resulted in incomplete conversion of the starting material (entry 13). Importantly, we found that analogous conditions could be used to produce vinyl chloride $\mathbf{4}$ and bromide $\mathbf{5}$ simply by substituting TBAF with TBACl or TBABr (entries 14,15). ${ }^{6}$ 
With these results in hand, we began to explore the scope of this reaction. Initial efforts focused on utilizing electron-rich arenes, such as the $p$-anisole substituent of boronate $\mathbf{3}$, that would stabilize putative carbocation intermediates. Strongly electron-donating substituents produced vinyl fluorides $6-9$ in $50-82 \%$ yield (Scheme 2). Vinyl fluoride 7 was also isolated in good yield utilizing only three equivalents of TBAF on $1 \mathrm{mmol}$ scale. Alkenyl boronic esters bearing meta substituents and an ortho or para donor were also tolerated, yielding vinyl fluorides 10 and 11 in $59 \%$ and $47 \%$ yield respectively. Additionally, novel fluoro-analogue 12 of chlorotrianisene, a nonsteroidal estrogen ${ }^{9 a}$, was generated in $60 \%$ yield. Other appended ring sizes and alkyl chains also led to production of the vinyl fluoride (13-16). Constant voltage conditions were key to produce electron-rich aniline fluoride product 16.

Table 1. Optimization of fluorination from vinyl trifluoroborate 1 and pinacol
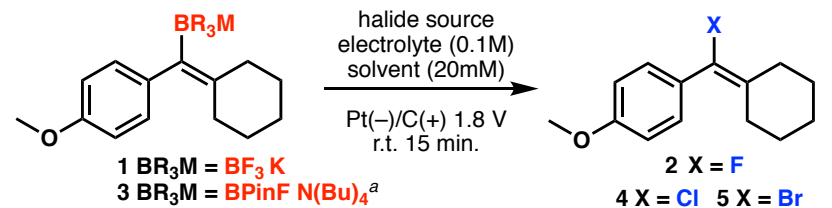

boronate 3 . Isolated yields.

\begin{tabular}{|c|c|c|c|c|c|}
\hline Entry & $\begin{array}{l}\text { Starting } \\
\text { Material }\end{array}$ & Solvent & $\begin{array}{l}\text { Electrolyte } \\
(0.1 \mathrm{M})\end{array}$ & $\begin{array}{l}\text { Halide Source } \\
\text { (equiv) }\end{array}$ & Yield \\
\hline 1 & 1 & $D C M$ & $\mathrm{TBABF}_{4}$ & $\begin{array}{c}\text { TBAF } \cdot\left(\mathrm{H}_{2} \mathrm{O}\right)_{3} \\
\text { (5 equiv) }\end{array}$ & $42 \%^{b}$ \\
\hline 2 & 1 & THF & $\mathrm{TBABF}_{4}$ & $\begin{array}{l}\text { TBAF } \cdot\left(\mathrm{H}_{2} \mathrm{O}\right)_{3} \\
\text { (5 equiv) }\end{array}$ & $<5 \% b$ \\
\hline 3 & 1 & $D M F$ & $\mathrm{TBABF}_{4}$ & $\begin{array}{l}\text { TBAF } \cdot\left(\mathrm{H}_{2} \mathrm{O}\right)_{3} \\
\text { (5 equiv) }\end{array}$ & n.d. \\
\hline 4 & 1 & $\mathrm{MeCN}$ & $\mathrm{TBABF}_{4}$ & $\begin{array}{c}T B A F \cdot\left(\mathrm{H}_{2} \mathrm{O}\right)_{3} \\
\text { (5 equiv) }\end{array}$ & $65 \%$ \\
\hline 5 & 3 & $\mathrm{MeCN}$ & $\mathrm{TBABF}_{4}$ & $\begin{array}{l}T B A F \cdot\left(\mathrm{H}_{2} \mathrm{O}\right)_{3} \\
\text { (5 equiv) }\end{array}$ & $70 \%$ \\
\hline 6 & 3 & $\mathrm{MeCN}$ & $\mathrm{TBABF}_{4}$ & $\begin{array}{l}\text { TBAF } \cdot\left(\mathrm{H}_{2} \mathrm{O}\right)_{3} \\
\text { (3 equiv) }\end{array}$ & $62 \%$ \\
\hline 7 & 3 & $\mathrm{MeCN}$ & $\mathrm{TBABF}_{4}$ & $\begin{array}{l}T B A F \cdot\left(\mathrm{H}_{2} \mathrm{O}\right)_{3} \\
\text { (2 equiv) }\end{array}$ & $50 \%$ \\
\hline 8 & 3 & $\mathrm{MeCN}$ & $\mathrm{TBABF}_{4}$ & $\begin{array}{l}T M A F \cdot\left(\mathrm{H}_{2} \mathrm{O}\right)_{4} \\
\text { (5 equiv) }\end{array}$ & $49 \%$ \\
\hline 9 & 3 & $\mathrm{MeCN}$ & $\mathrm{TBABF}_{4}$ & $\begin{array}{c}T B A F \cdot(t B u O H)_{4} \\
(5 \text { equiv })\end{array}$ & $58 \%$ \\
\hline 10 & 3 & $\mathrm{MeCN}$ & $\mathrm{TBABF}_{4}$ & $\begin{array}{c}K F+18-C r o w n-6 \\
\text { (10 equiv) }\end{array}$ & n.d. \\
\hline 11 & 3 & $\mathrm{MeCN}$ & $\mathrm{TBABF}_{4}$ & TBAT (5 equiv) & $40 \%^{b}$ \\
\hline 12 & 3 & $\mathrm{MeCN}$ & $T_{B A P F_{6}}$ & $\begin{array}{c}T B A F \cdot\left(\mathrm{H}_{2} \mathrm{O}\right)_{3} \\
\quad(5 \text { equiv })\end{array}$ & $54 \%^{b}$ \\
\hline 13 & 3 & $\mathrm{MeCN}$ & $\mathrm{TBABF}_{4}$ & $\begin{array}{c}T B A F \cdot\left(\mathrm{H}_{2} \mathrm{O}\right)_{3} \\
\quad(5 \text { equiv })\end{array}$ & $19 \% b, c$ \\
\hline 14 & 3 & $M e C N$ & $\mathrm{TBABF}_{4}$ & TBACI (6 equiv) & $68 \%$ \\
\hline 15 & 1 & $\mathrm{MeCN}$ & $\mathrm{TBABr}$ & - & $57 \%$ \\
\hline
\end{tabular}

[a] Formed in situ from the pinacol boronic ester. [b] ${ }^{19} \mathrm{~F}$ NMR yield with fluorobenzene as an internal standard [c] Added $50 \mathrm{mg}$ mol sieves, MeCN distilled over $\mathrm{CaH}_{2}$ and dried over mol sieves. TBAT=tetrabutyl ammonium

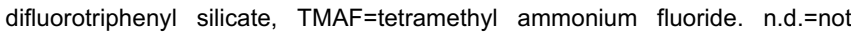
detected

Less electron-donating substituents were tolerated, but led to incomplete conversion even at higher applied potentials (17-19). Notably, these $\mathrm{N}-\mathrm{H}$ containing compounds are not tolerated under routine Lewis acid promoted vinyl carbocation formation, but are commonly seen in natural products and drug molecules. ${ }^{2,9 b}$ The boronic ester bearing a simple phenyl ring did not lead to formation of vinyl fluoride $\mathbf{2 0}$, even under forcing conditions.

Throughout these studies we observed that only electron-rich arenes were competent in this transformation. Yields increased with decreasing Hammet $\sigma_{p}$ parameter, suggesting that there was a carbocation formed at the carbon once bearing the boronic ester. The trend of decreasing yield, $6>13>17>19$, with corresponding $\sigma_{p}$ values of $-0.81<-0.27<-0.17<0.00$ for the respective para donor substituents, was observed. ${ }^{10}$ Additionally, if a meta-methoxy group were present on the arene, an electron-withdrawing substituent with $\sigma_{\mathrm{m}}=+0.12,21$ was not formed. ${ }^{6,10}$ This trend suggested the formation of a carbocation intermediate, and so we carried out further mechanistic studies to investigate the intermediacy of a vinyl carbocation.<smiles>[R]/C(Cc1ccccc1)=C(\[R])c1ccccc1</smiles>

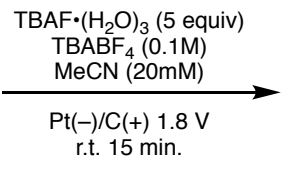<smiles>[R]C([R])=C(F)c1ccccc1</smiles><smiles>COc1ccccc1C(F)=C1CCCCC1</smiles><smiles>[13CH3]</smiles><smiles>COc1cc(OC)c(C(F)=C2CCCCC2)c(OC)c1</smiles><smiles>FC(=C1CCCCC1)c1cccs1</smiles><smiles>COc1ccc(C(F)=C2CCCCC2)cc1OC</smiles><smiles>Cc1ccc(O[14C]([18F])[18F])c(C(F)=C2CCCCC2)c1</smiles>

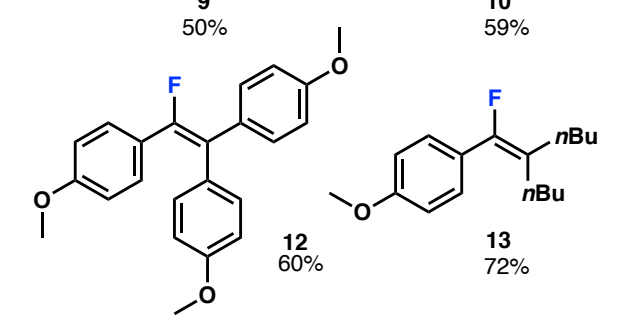<smiles>CCCCCCCCCCCCCCCCCCCCCCCC</smiles><smiles>CC1(C)Oc2ccc(C(F)=C3CCCC3)cc2O1</smiles>
15
$68 \%$<smiles>CNc1ccc(C(F)=C2CCC(C(=O)O)C2)cc1</smiles><smiles>FC(=C1CCCCC1)c1ccc(Nc2ccccc2)cc1</smiles><smiles>CN(C(=O)OC(C)(C)C)c1ccc(C(F)=C2CCCC2)cc1</smiles><smiles>CC(C)(C)Sc1ccc(C(F)=C2CCCCC2)cc1</smiles><smiles>FC(=C1CCCCC1)c1ccccc1</smiles>
$52 \%$ (20\% recovered s.m.) $\quad 20 \%$ (59\% recovered s.m.) 20 n.d.<smiles>COc1cccc(C(F)=C2CCCCC2)c1</smiles>

n.d.

Scheme 2. Scope of alkenyl boronic ester electrochemical fluorination. Isolated yields. [a] 3 equiv of TBAF on $1 \mathrm{mmol}$ scale. [b] Isolated as a 9:1 mixture of fluoride:styrene. [c] $+0.8 \mathrm{~V}$ vs SCE. n.d.=not detected

First we probed for canonical vinyl carbocation reactivity. One classic mode of reactivity of vinyl carbocations is E1 elimination to form alkyne products. ${ }^{11}$ Upon subjection of alkenyl boronic ester 22 to the reaction conditions, alkyne 23 , the product of $E 1$ elimination of putative vinyl carbocation 24, was observed in moderate yield (Scheme 3a). A similar elimination occurs with trisubstituted alkenyl 
boronic esters to yield alkyne. ${ }^{6}$ This does however limit the substrates for fluorination to tetrasubstituted alkenyl boronates.

In order to rule out production of this alkyne from a vinyl fluoride intermediate, styrenyl fluoride $\mathbf{2 5}$ was prepared and subjected to the reaction conditions. No conversion to the alkyne was observed and the starting material was recovered in quantitative yield.

To probe the intermediacy of a linear vinyl carbocation intermediate, unsymmetric alkenyl boronic ester $\mathbf{2 6}$ was prepared as a single isomer. Subjection of this material to the reaction conditions yielded a mixture of $Z: E$ vinyl fluoride products 26 in a $6.25: 1$ ratio (Scheme $3 b$ ). This supports fluoride nucleophilic attack of a linear intermediate as opposed to other stereo retentive pathways.

Vinyl carbocations are also known to undergo $\mathrm{C}-\mathrm{C}$ bond forming reactions with arene nucleophiles. ${ }^{2,11}$ To explore Friedel-Crafts reactivity, $\mathbf{1}$ was subjected to the reaction conditions in the presence of 10 equivalents of electron rich $\mathrm{N}-\mathrm{Me}$ pyrrole instead of TBAF. Pyrrole nucleophiles have been observed to trap similar $p$-anisole substituted vinyl carbocations generated by photolysis. ${ }^{2 \mathrm{~d}}$ In the event, arylated products 28 were produced in a $2.7: 1$ ratio in $48 \%$ yield (Scheme $3 \mathrm{c}$ ). This product ratio further supports a vinyl carbocation intermediate as opposed to a radical intermediate, as such radical additions are reported to exclusively form $\mathrm{C} 2$ addition products. $^{12}$

$\mathrm{C}-\mathrm{C}$ bond forming reactions via intramolecular $\mathrm{C}-\mathrm{H}$ insertion reactions have also been observed in several studies of vinyl a) Elimination reactivity
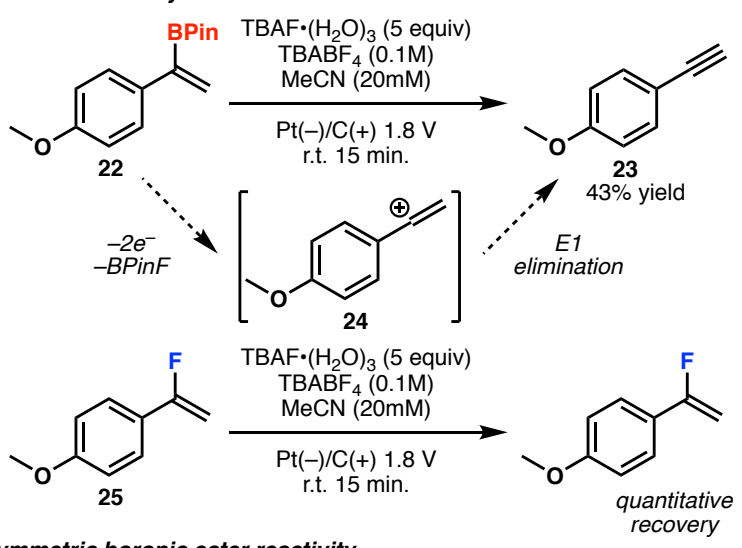

b) Unsymmetric boronic ester reactivity

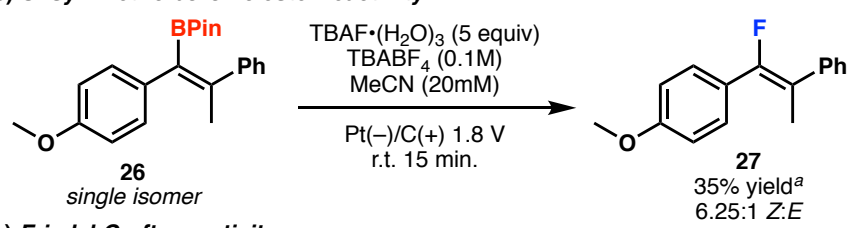

c) Friedel-Crafts reactivity
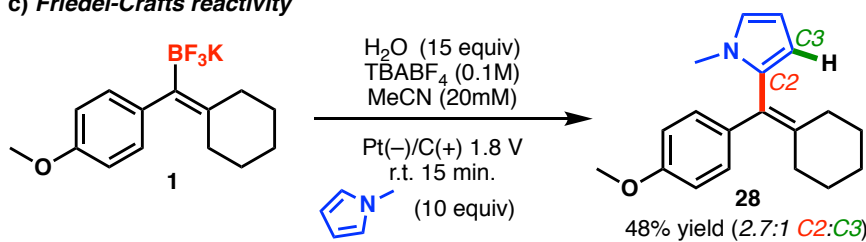

d) $\mathrm{C}-\mathrm{H}$ insertion reactivity

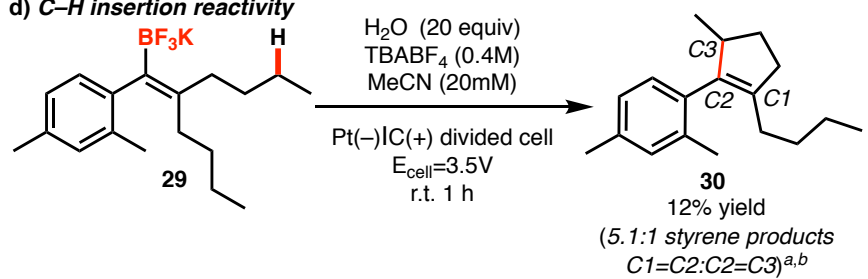

Scheme 3. Mechanistic experiments to probe for vinyl carbocation reactivity (a) Elimination reactivity suggesting vinyl carbocation intermediate. (b) Unsymmetric alkenyl boronic ester reactivity. (c) Friedel-Crafts reactivity with $\mathrm{N}$-Me pyrrole. (d) $\mathrm{C}-\mathrm{H}$ Insertion reactivity. Isolated yields. [a] Yield determined by ${ }^{1} \mathrm{H}$ NMR with an internal standard. [b] Ratio of styrene olefin isomers determined by GC-FID. carbocations. ${ }^{3 g-k}$ In order to probe for this type of reactivity, the trifluoroborate salt 29 with appended alkyl chains was prepared and subjected to electrolysis in a divided cell. In the presence of fluoride these products were not observed, and so the pre-activated trifluoroborate was used. Gratifyingly, we observed production of the $\mathrm{C}-\mathrm{H}$ insertion products $\mathbf{3 0}$ as a mixture of olefin isomers, albeit in low yield (Scheme 3d). This diminished yield is due to the subsequent decomposition of the electron-rich tetrasubstituted styrene products under the oxidative conditions. ${ }^{6}$

To further investigate the mechanistic pathway to the proposed vinyl carbocation we performed cyclic voltammetry experiments. The tetrabutylammonium salt of 1 showed two irreversible oxidative events at $+1.12 \mathrm{~V}$ and $+1.56 \mathrm{~V}$ vs SCE (Scheme 4a). ${ }^{6}$ This experiment demonstrated evidence for a two-electron oxidation process; additionally, bulk electrolysis coulometry at a constant potential of $1.8 \mathrm{~V}$ vs SCE further confirmed this with a calculated Faradaic efficiency for two-electrons per boronate substrate of $73 \%{ }^{6}$ We hypothesized that the initial oxidation would yield a vinyl radical, as is proposed for the oxidation of a variety of alkyl trifluoroborates. ${ }^{13}$ In order to probe for this intermediate, trifluoroborate 1 was subjected to the reaction conditions in the presence of deuterated H/D-atom donor propane thiol (Scheme 4b). Deuterium incorporation exclusively at the styrene position (31) was observed supporting the intermediacy of a vinyl radical. To determine if this radical intermediate was generated at the lower potential, trifluoroborate 1 was subjected to constant voltage electrolysis in the presence of $\mathrm{N}$ methyl pyrrole at $+1.1 \mathrm{~V}$ vs SCE (Scheme 4c). At this potential different regioselectivity was observed compared to at $+1.8 \mathrm{~V}$ (Scheme $3 \mathrm{~b}$ ); only the $\mathrm{C} 2$ arylation product was observed suggesting the presence of a radical. ${ }^{12}$ Furthermore, at this lower potential no vinyl fluoride products were observed in the presence of TBAF. ${ }^{5}$

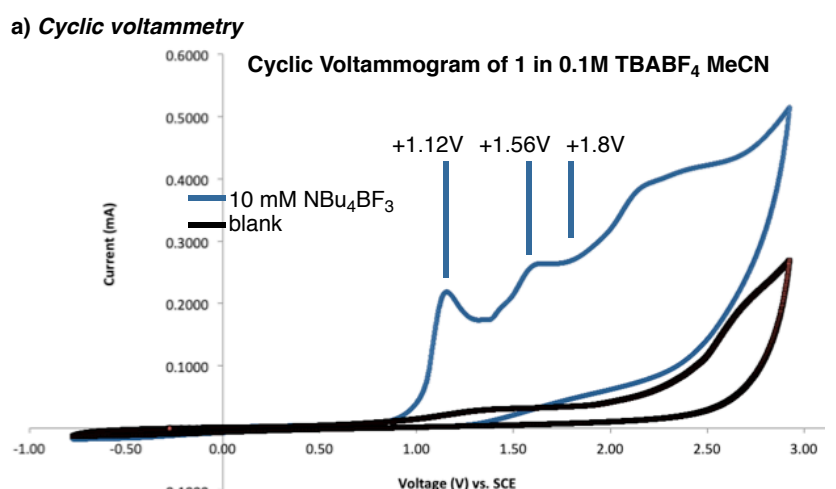

b) Vinyl radical trapping
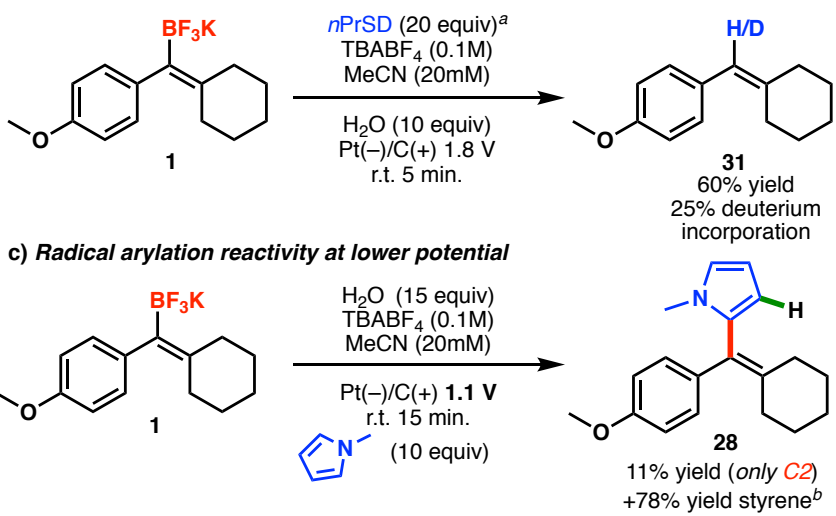

Scheme 4. Mechanistic experiments to probe for vinyl radical intermediate. (a) Cyclic voltammogram of the tetrabutylammonium salt of 1 in $0.1 \mathrm{M} \mathrm{TBABF}_{4}$ $\mathrm{MeCN}$ at $100 \mathrm{mV} / \mathrm{s}$. First and second oxidative waves and $+1.8 \mathrm{~V}$ of typical reaction highlighted. (b) Styrene products observed in the presence of $n \mathrm{PrSD}$. (c) Change of arylation regioselectivity at lower applied potential. [a] Propane thiol prepared at $77 \%$ deuteration by isotope exchange with $\mathrm{D}_{2} \mathrm{O}$ as determined by ${ }^{1} \mathrm{H}$ NMR. [b] Yields determined by ${ }^{1} \mathrm{H}$ NMR with an internal standard. $n \mathrm{PrSD}=$ deuterium incorporated $n$-propyl thiol.

With these combined experiments supporting the intermediacy of a vinyl radical after the first oxidation at $+1.1 \mathrm{~V}$ vs SCE, we propose 
the sequential ECE-type oxidation mechanism in Scheme 5. DFT calculations were performed to further understand the initial oxidation event. Initial in silico oxidation of the calculated HOMO of trifluoroborate anion 32 yielded delocalized radical cation $\mathbf{3 3}$, in good agreement with experimental data at a calculated potential of +1.04 $\mathrm{V}$ vs SCE (Scheme $5 \mathrm{a}$ ). We propose that this can subsequently eliminate $\mathrm{BF}_{3}$ to yield vinyl radical $\mathbf{3 4}$ that undergoes a second oxidation to yield vinyl carbocation 35 (Scheme $5 \mathrm{~b}$ ). In the case of the pinacol boronic esters, an equivalent of $\mathrm{BPin}-\mathrm{F}$ is produced that was observed by ${ }^{19} \mathrm{~F}$ and ${ }^{11} \mathrm{~B}$ NMR. ${ }^{6}$ This carbocation intermediate can be trapped by nucleophilic fluoride in solution to furnish vinyl fluoride product 2.

In conclusion, we report the novel generation of vinyl carbocations via an electrochemical potential; from a synthetic standpoint the products of these reactions have potential application in medicinal chemistry. Vinyl fluorides have been demonstrated to be effective enol mimics, ${ }^{14}$ are considered bioisosteres of the peptide bond ${ }^{15}$ and fluorinated drug compounds can often display exquisite pharmacokinetic properties and binding affinity compared to the parent $\mathrm{C}-\mathrm{H}$ containing compound. ${ }^{16}$ While there are several reports of conversion of aryl boronates to aryl fluorides, these reaction conditions commonly rely on the use electrophilic fluorine

a) Predicted initial oxidation

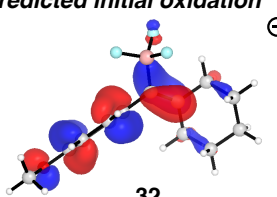

32

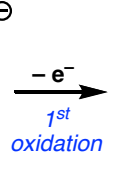

Lexidation

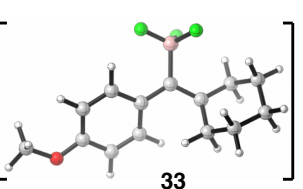

33

$1.04 \mathrm{~V}$ vs SCE (calculated oxidation potential)

1.12 V VS SCE (observed oxidation potential)

\section{b) Proposed mechanism}

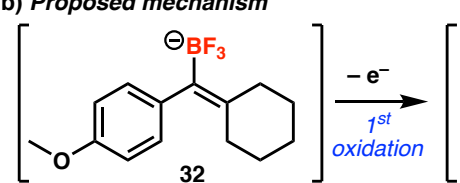
32<smiles>COc1ccc(C(F)=C2CCCCC2)cc1</smiles>

2

Scheme 5. (a) Predicted initial oxidation. (b) Proposed mechanism of boronate fluorination. Calculated HOMO and oxidation potential using (uMO6$2 X / 6-311++G(d, p) \quad \mathrm{cpcm}=$ acetonitrile // uM06-2X/6-31+G(d,p) $\mathrm{cpcm}=$ acetonitrile)

reagents and silver salts. ${ }^{17}$ The use of easy-to-handle nucleophilic fluoride reagents has recently been reported for generation of aryl fluorides from aryl boronates, but there are few examples of the conversion of alkenyl boronates to vinyl fluorides. ${ }^{17,18}$ Moreover, vinyl fluorides are often synthesized from alkynes, yielding di- or trisubstituted alkene products, while methods to access fully substituted vinyl fluorides typically require prefunctionalized fluorination reagents. . $^{4,20}$ This electrochemical method features short reaction times in moderate to good yield. Additionally, mechanistic studies support the intermediacy of a vinyl radical followed by a second oxidation to a vinyl cation; this evidence suggests that electrochemical oxidation may be a viable strategy to access dicoordinate vinyl carbocations, emerging intermediates in organic synthesis. ${ }^{21}$

\section{Acknowledgements}

Financial support for this work was generously provided by the Alfred P. Sloan Foundation (to H.M.N.), the NIH-NIGMS (R35 GM128936 to H.M.N.), and the National Science Foundation (CHE-1764328 to K.N.H and DGE-1650604 to B.W.). B.W. thanks the Christopher S. Foote Fellowship for funding. The authors thank the Mass Spectrometry facility at the University of California, Irvine. Computations were performed on the Hoffman2 cluster at UCLA. Cyclic voltammetry was performed in the laboratory of Prof. Chong Liu with Benjamin Natinsky. Finally, we thank Prof. Song Lin and Juno Siu for useful discussions.

The authors declare no conflict of interest.

Keywords: vinyl carbocations • fluorination • electrochemistry • alkenyl boronates $\cdot$ vinyl fluorides

[1] [a] G. A. Olah J. Org. Chem. 2001, 66, 5943-5957. [b] R. R. Naredla, D. A. Klumpp, Chem. Rev. 2013, 113, 6905-6948.

[2] [a] T. Müller, M. Juhasz, C. A. Reed, Angew. Chem. 2004, 116, 15691572; Angew. Chem. Int. Ed. 2004, 43, 1543-1546. [b] A. Bismuto, G. S. Nichol, F. Duarte, M. J. Cowley, S. Thomas, Angew. Chem. 2020 132, 12831-12835; Angew. Chem. Int. Ed. 2020, 59, 12731-12735. [c] W. D. Pfeifer, C. A. Bahn, P. v. R. Schleyer, S. Bocher, E. C. Harding, K. Hummel, M. Hanack, P. J. Stang J. Am. Chem. Soc. 1971, 93, 1513-1516. [d] P. A. Byrne, S. Kobayashi, E. -U. Wüthwein, J. Ammer, H. Mayr, J. Am. Chem. Soc. 2017, 139, 1499-1511. [e] T. Kitamura, S Kobayashi, H. Taniguchi, J. Org. Chem. 1982, 47, 2323-2328. [f] M. Slegt, R. Grohnheid, D. van der Vlugt, M. Ochiai, T. Okuyama, H. Zuilhof, H. S. Overkleeft, G. Loder J. Org. Chem. 2006, 71, 2227-2235 [g] U. Biermann, R. Koch, J. O. Metzger, Angew. Chem. 2006, 118 3146-3150; Angew. Chem. Int. Ed. 2006, 45, 3076-3079. [h] S. E. Cleary, M. J. Hensinger, M. Brewer, Chem. Sci. 2017, 8, 6810-6814. [i] S. Popov, B. Shao, A. L. Bagdasarian, T. R. Benton, L. Zou, Z. Yang, K. N. Houk, H. M. Nelson, Science 2018, 361, 381-387. [j] B. Wigman, S. Popov, A. L. Bagdasarian, B. Shao, T. R. Benton, S. P. Fisher, V. Lavallo, K. N. Houk, H. M. Nelson, J. Am. Chem. Soc. 2019, 141 9140-9144. [k] F. Zhang, S. Das, A. J. Walkinshaw, A. Casitas, M. Taylor, M. G. Suero, M. J. Gaunt, J. Am. Chem. Soc. 2014, 136, 88518854. [l] S. Schroeder, C. Strauch, N. Gaelings, M. Niggemann, Angew. Chem. 2019, 131, 5173-5177; Angew. Chem., Int. Ed. 2019, 58, 51195123.

[3] [a] H. Hofer, M. Moest, Justus Liebigs Ann. Chem. 1902, 323, 284-323. [b] E. J. Corey, N. L. Bauld, R. T. La Londe, J. Jr. Casanova, E. T. Kaiser, J. Am. Chem. Soc. 1960, 82, 2645-2646. [c] J. -I. Yoshida, A. Shimizu, R. Hayashi, Chem. Rev. 2018, 118, 4702-4730. [d] M. Okajima, K. Soga, T. Nokami, S. Suga, J.-I. Yoshida, Org. Lett. 2006, 8, 5005-5007.

[4] Examples of tetrasubstituted vinyl fluoride syntheses: [a] X. S. Lei, Lei, G. Dutheuil, X. Pannecoucke, J. C. Quirion, Org. Lett. 2004, 6, 21012104. [b] K. Pomeisl, J. Cejka, J. Kvicala, O. Paleta, Eur. J. Org. Chem. 2007, 37, 5917-5925. [c] P. Van der Veken, I. Kertesz, K. Senten, A Haemers, K. Augustyns, Tetrahedron Lett. 2003, 44, 6231-6234. [d] A. J. Zapata, Y. H. Gu, G. B. Hammond, J. Org. Chem. 2000, 65, 227234. [e] D. Chevrie, T. Lequeux, J. P. Demoute, S. Pazenok, Tetrahedron Lett. 2003, 44, 8127-8130. [e] L. G. Zhu, C. F. Ni, Y. C Zhao, J. B. Hu, Tetrahedron, 2010, 66, 5089-5100. [f] A. K. Ghosh, S. Banerjee, S. Sinha, S. B. Kang, B. Zajc, J. Org. Chem. 2009, 74, 3689 3697. [g] J. Lin, J. T. Welch, Tetrahedron Lett. 1998, 39, 9613-9616. [h] M. Yoshimatsu, Y. Murase, A. Itoh, G. Tanabe, O. Muraoka, Chem. Lett. 2005, 34, 998-999. [i] Y. Usuki, M. Iwaoka, S. Tomoda, J. Chem Soc., Chem. Commun. 1992, 16, 1148-1150. [k] K. Sano, T. Fukuhara, S. Hara, J. Fluorine Chem. 2009, 130, 708-713. [l] B. Dolensky, K. L. Kirk, J. Org. Chem. 2002, 67, 3468-3473. [m] G. Landelle, P. A. Champagne, X. Barbeau, J.-F. Paquin, Org. Lett. 2009, 11, 681-684. [n] G. Dutheuil, S. Couve-Bonnaire, X. Pannecoucke, Tetrahedron, 
2009, 65, 6034-6038. [o] H. Q. Luo, X. H. Hu, T.-P. Loh, Tetrahedron Lett. 2010, 51, 1041-1043. [p] for an in depth review see: G. Landelle, M. Bergeron, M. -O. Turcotte-Savard, J. -F. Paquin, Chem. Soc. Rev. 2011, 40, 2867-2908.

[5] E. W. Webb, J. B. Park, E. L. Cole, D. J. Donnelly, S. J. Bonacorsi, W. R. Ewing, A. G. Doyle, J. Am. Chem. Soc. 2020, 142, 9493-9500.

[6] See supporting information for details.

[7] [a] J. Suzuki, M. Tanigawa, S. Inagi, T. Fuchigami, ChemElectroChem 2016, 3, 2078-2083. [b] J. H Morris, H. J. Gysling, D. Reed Chem. Rev. 1985, 85, 51-76. [c] G. A. Molander, V. Colombel, V. Braz, Org. Lett. 2011, 13, 1852-1855. [d] S. R. Neufeldt, C. K. Seigerman, M. S Sanford, Org. Lett. 2013, 15, 2302-2305. [e] H. G. Lee, T. D. Chung, S. Y. Go, H. Chung, S. J. Shin, S. An, J. H. Youn, T. Y. Im, J. Y. Kim, 2021 ChemRxiv preprint DOI: 10.33774/chemrxiv-2021-bvf1।

[8] A. J. J. Lennox, J. E. Nutting, S. S. Stahl, Chem. Sci. 2018, 9, 356-361.

[9] [a] A. Luniwal, R. Jetson, P. Erhardt, Analgoue-based drug discovery. Wiley, Hoboken, 2012, p. 165-185. [b] N. Kerru, L. Hummidi, S. Maddila, K. K. Gangu, S. B. Jonnalagadda Molecules 2020, 25, 1909.

[10] C. Hansch, A. Leo, R. W. Taft, Chem. Rev. 1991, 91, 165-195. (Note: $\sigma_{p}$ value for $-\mathrm{SMe}$ and $-\mathrm{NHCO}_{2} \mathrm{Me}$ substituents used).

[11] [a] P. J. Stang, Z. Rappoport, M. Hanack, L. R. Subramanian, Vinyl Cations, Academic Press, New York, 1979, p. 68-76. [b] Z. Rappoport, P. Shulman, M. Thuval, J. Am. Chem. Soc. 1978, 100, 7041-7051.

[12] [a] E. Kocaoğlu, M. A. Karaman, H. Tokogöz, O. Talaz, ACS Omega, 2017, 2, 5000-5004. [b] Z. Li, V. Gandon, C. Bour, Chem. Comm. 2020 , 56,6507-6510. [c] A. A. Suleymanov, M. Doll, A. Ruggi, R. Scopelliti, F. Fadaie-Tirani, Angew. Chem. 2020, 132, 10043-10047; Angew. Chem. Int. Ed. 2020, 59, 9957-9961.

[13] J. K. Matsui, S. B. Lang, D. R. Heitz, G. A. Molander, ACS Catal. 2017, 7, 2563-2575.

[14] J. P. Burkhart, P. M. Weintraub, C. A. Gates, R. J. Resvick, R. J. Vaz, D. Friedrich, M. R. Angelastro, P. Bey, N. P. Peet, Bioorg. Med. Chem. 2002, 10, 929-934.

[15] [a] C. G. Wermuth, D. Aldous, P. Raboisson, D. Rognan, The practice of medicinal chemistry, Academic Press, Oxford, 2015, p. 210-212. [b] N. S. Chandrakumar, P. K. Yonan, A. Stapelfeld, M. Savage, E. Rorbacher, P. C. Contreras, D. Hammond, J. Med. Chem. 1992, 35, 223-233.

[16] [a] J. Wang, M. S-. Roselló, J. L. Aceña, C. D. Pozo, A. E. Sorochinsky, S. Fustero, V. A. Soloshonok, H. Liu, Chem. Rev. 2014, 114, 24322506. [b] N. A. Meanwell, J. Med. Chem. 2018, 61, 5822-5880.

[17] [a] T. Furuya, T. Ritter, Org. Lett. 2009, 11, 2860-2863. [b] Y. Ye, M. S. Sanford, J. Am. Chem. Soc. 2013, 135, 4648-4651. [c] P. S. Fier, J. Luo, J. F. Hartwig, J. Am. Chem. Soc. 2013, 135, 2552-2559.

[18] Y. Ye, S. D. Schimler, P. S. Hanley, M. S. Sanford, J. Am. Chem. Soc. 2013, 135, 16292-16295.

[19] O. E. Okoromoba, J. Han, G. B. Hammond, B. Xu, J. Am. Chem. Soc. 2014, 136, 14381-14384.

[20] [a] M. Drouin, J. -D. Hamel, J. -F. Paquin, Synthesis 2018, 50, 881955. [b] H. Yanai, T. Taguchi, Eur. J. Org. Chem. 2011, 30, 5939-5954. [c] J. R. McCarthy, D. P. Matthews, D. M. Stemerick, E. W. Huber, P. Bey, B. J. Lippert, R. D. Snyder, P. S. Sunkara J. Am. Chem. Soc. 1991 113, 7439-7440. [d] D. J. Burton, P. E. Greenlimb, J. Org. Chem. 1975, 40, 2796-2800.

[21] M. Niggemann, S. Gao, Angew. Chem. 2018, 130, 17186-17188: Angew. Chem. Int. Ed. 2018, 57, 16942-16944. 


\section{Entry for the Table of Contents}

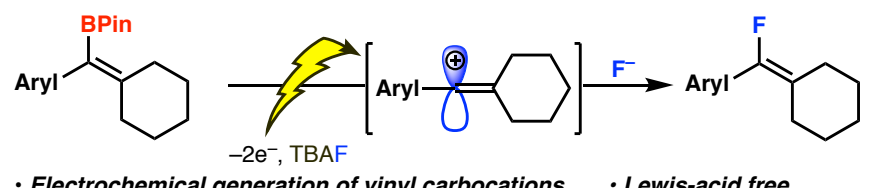

- Electrochemical generation of vinyl carbocations $\quad \cdot$ Lewis-acid free

Insert text for Table of Contents here.

Vinyl carbocations were generated via single-electron oxidation of vinyl boronates using electrical potentials. This electrochemical process enabled the formation of these reactive species without the use of Lewis or Brønsted acids. The intermediate vinyl carbocations were trapped with nucelophilic fluoride sources to yield vinyl fluorides; the production of new $\mathrm{C}-\mathrm{C}, \mathrm{C}-\mathrm{Cl}$, and $\mathrm{C}-\mathrm{Br}$ bonds was also demonstrated. 